Multiple-choice tests in advanced mathematics 


\title{
Multiple-choice tests in advanced mathematics
}

\author{
C. Plumpton, Ph.D.
}

Moderator in Mathematics, University of London School Examinations Department; formerly Reader in Engineering Mathematics, Queen Mary College, University of London

\section{E. Shipton, B.Sc.}

Teacher-moderator in Advanced-level Mathematics, University of London School Examinations Department formerly Deputy Head, Owen's School,

\author{
Potters Bar
}

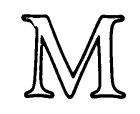

Macmillan Education

London and Basingstoke 


\section{A note on using this book}

The rubrics for answering questions in the various sections of the tests do not precede each section as they would do in real examination papers. Instead, in order to conserve space in the book, a pull-out section with rubrics printed on it is included at the end. When the book is being used the pull-out can be kept extended and the rubrics read by the student as needed as he works through the tests.

This is a practical if unusual approach and one that saves considerable repetition and wasted space in the main body of the book.

All rights reserved. No part of this publication may be reproduced or transmitted, in any form or by any means, without permission.

First published 1983

Published by

Macmillan Education Limited

Houndmills Basingstoke Hampshire RG21 2XS

and London

Associated companies throughout the world 


\section{Preface}

For some years, multiple-choice questions have been used in some GCE A-level examinations in mathematics. There is, therefore, a great need for specimen questions and papers of this type for use in mock examinations and the general preparation of A-level students, in addition to the past papers of the GCE boards, where these are available. Further, the acceptance by the GCE boards of 'common-core' based syllabuses in unified 'modern-traditional' mathematics at A-level, and the use of 'no-choice' examination papers implies that students ought to cover the new syllabus completely. No longer can some topics be conveniently ignored, particularly as university departments in pure and applied science are tending to assume a thorough knowledge of the 'common-core' syllabus allied to a sound competence in manipulative skills.

This book is particularly aimed at students preparing for the new A-level Syllabus B subjects, Mathematics, Further Mathematics, Pure Mathematics, Applied Mathematics, and Pure Mathematics with Statistics first examined by the London GCE Board in June 1982 , but should be of great value to students taking the A-level examinations of other boards, particularly those which include a multiple-choice element.

There is a further use for the question papers in this book. Multiple-choice papers are designed to give a good coverage of the syllabus. It is felt, therefore, that, whether or not multiple-choice papers form part of an examination, a student preparing for any GCE A-level examination in mathematics or any future examination at this level, particularly one based on a unified approach, would find it helpful to use these papers as revision exercises, noting the questions which prove difficult and thus reinforcing the need to revise particular areas of the syllabus.

Many of the questions in this book have been pretested at Owen's School by a group of pupils entered for the June 1982 examination. This is, of course, very limited pretesting but, on the other hand, both authors have been involved in the setting and moderation of A-level multiple-choice questions from the time when this type of paper was first introduced by the London Board. This means that they have looked at literally hundreds of questions with a critical eye and they feel that this experience has enabled them to set well-balanced papers with questions carefully graded for degree of difficulty.

Tests 1-8 contain only questions on 'pure' mathematics and are intended for students entered for an examination with a 'common-core' element. Tests 9-12 on Further Mathematics, containing both pure and applied items, and Tests 13 and 14, containing applied items only, are intended for more advanced students and contain some more difficult questions. Nevertheless, a time limit of one hour should be allowed for each test.

The general philosophy, jargon, etc. of multiple-choice questions is discussed in the introduction to the O-level book, Multiple Choice Mathematics by C. Plumpton (Macmillan Education, 1981), and will not be repeated here. The simple multiple-choice and multiple-completion item types of the O-level book occur here also, but in Tests 9-14 of this book additional item types are introduced. These are relationship analysis (Section III), data necessity (Section IV) and data sufficiency (Section V) items. These items enable coverage of topics which are difficult or unfair to examine by longer structured questions. Indeed, these more sophisticated item types are a far better test of mathematical understanding than some longer questions in which candidates may be applying a method or technique which they have learnt but have not properly understood. Section III (relationship analysis) tests insight into the relationship between mathematical statements in a way which is not covered by any other type of question. Both the Section IV (data necessity) and Section V (data sufficiency) items enable the candidate to show ability in analysing a question without the 'slog' of working it out. They also provide some training in such considerations as the dimensions of an answer, thus helping candidates to avoid some of the grosser errors met with in answers to conventional Applied Mathematics questions.

If candidates are given these papers to work through on a regular basis during the second year of their course, it will be found that this provides invaluable revision work as it will keep all the syllabus topics constantly under review. It is, indeed, hoped that each question paper in this book can be used as a specimen paper in relation to the multiple-choice papers of the London A level Mathematics Syllabus B examination.
C. Plumpton

E. Shipton 